\title{
Grade R educators voluntarily share their mathematics practices: Authentic realities in South Africa showcased
}

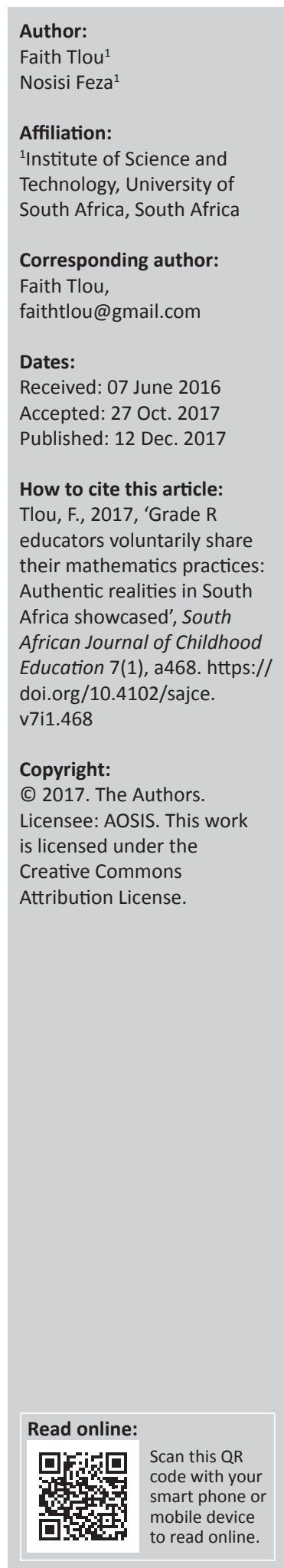

In South Africa's reception classes (Grade R), the harsh reality is that the sector is beset by serious challenges. As part of a broader professional development study, this article focuses on the actual operations of Grade R educators as they conduct mathematics lessons using video technology to record their teaching. An observation tool adapted from Clements and Sarama is used to determine the quality of mathematics instruction, and to provide recommendations for bridging the gaps observed. Fourteen Grade R classes were video-recorded as part of the bigger project, with the educators themselves selecting three lessons per class to showcase their practices. For this article, the authors employed a qualitative approach guided by Vygotsky's conceptual development of knowledge theory. A thematic analysis was conducted, mediated by the lesson observation instrument. The findings indicate that Grade R educators lack structure and purpose in their instructional activities. Even when sound content knowledge is demonstrated, the instruction tends to be teacher-centred.

\section{Introduction}

South Africa's education system has experienced many performance-related challenges in mathematics over the years. Evaluations and research have pointed to the generally poor mathematics early learning experiences of South African learners (Feza 2013). In addition, studies have revealed that Grade $\mathrm{R}$ (the reception year) is subjected to disturbing, multifaceted challenges that are a cause for concern among stakeholders, who view current practices as being out of step with policy guidelines (Artmore, Van Niekerk \& Ashley-Cooper 2012; Excell \& Linington 2011; Hoadley 2013; Samuels et al. 2015). Among the challenges facing this sector are poorly trained educators who have a minimum of content knowledge of mathematics (Spaull 2013), have poor classroom practices (Feza 2013) and are inept at the use of technology (Mdlongwa 2012). Another documented concern is poor or inadequate infrastructure, which results in learners being packed into overcrowded classrooms (Artmore et al. 2012; Biersteker 2010). The finding that many educators do not have the subject knowledge required to teach mathematics is a major challenge, because there is overwhelming evidence that certain educators cannot even explain concepts that young learners are expected to deal with (Feza 2016; NEEDU 2013; Schmidt, Cogan \& Houang 2011).

The aim of this study was to highlight current Grade R educator practices in teaching mathematics, from video lessons captured from educators voluntarily. To this end, educators were allowed to select the lessons they wanted to share, which means that voluntary showcasing became a tool for professional development. This means that this study explores how the educators mediate mathematics learning and how they develop conceptual understanding of numeracy.

\section{Related literature \\ Conceptual development}

Existing research emphasises the importance of developing conceptual understanding to make knowledge useful. International studies (e.g. TIMMS 2011 cited in Mullis et al. 2012) reveal that the biggest challenge facing underperforming learners is the inability to apply their knowledge and comprehension. This becomes an obstacle to learning in general, as their acquired knowledge becomes useless. Kozulin (2003) defines conceptual understanding as encompassing higher mental processes, asserting that for educators to be able to develop these processes their teaching should integrate learners' cultural tools. This refers to a combination of what learners bring to the classroom along with the new idea to be studied. In addition, Kozulin (2003) states that any 
new idea needs to be connected to learners' existing ideas and experiences, for it to be fully understood.

\section{Mediation of learning}

Vygotsky's (1978) sociocultural theory states that social interfaces and traditional institutions of learning (such as schools and classrooms) have significant roles to play in a learner's intellectual development (Clements \& Sarama 2014; Donato \& MacCormick 1994; Edwards 2003). Hence, mediation is important for making sense of, and developing, higher mental processes.

\section{Learning potential}

Learners' learning potential cannot be observed without identifying their actual level of thinking. The educator therefore has to acknowledge the importance of identifying the actual thinking level of his or her learners, as well as their potential level, in order to aim any instruction at the correct level (Vygotsky 1978). Scholars like Vygotsky (1978) urge that first the educator must be an expert capable of locating the learner's level of operation, which he names the Zone of Proximal Development (ZPD). Vygotsky introduced the ZPD as the learner's actual level of thinking. At this point, the educator assists the learner with cues as well as scaffolding of relevant information. The learner then makes associations and connections he or she would otherwise fail to make without the stimulation. The argument buttressed by Clements and Sarama (2014) traces the developmental pathways children follow in order to develop mathematical competencies in line with their class level of learning. Thus, an expert educator would not fail to aim at the levels that connect with the child's developmental stages. The possible next level is known as the learner's 'learning potential'. Clements and Sarama unpack Vygotsky's ZPD into developmental progressions in their theory of learning trajectories. These progressions are the levels learners must reach before being able to move on to a desired or next level. The educator is a critical collaborator who provides the scaffolding knowledge that enables the learner to complete a task. However, currently, competencies of Grade R educators in the non-affluent, low socioeconomic sector schools fall far short of such expertise (Feza 2012a, 2013; Siyepu 2013).

\section{Multiculturalism}

Vygotsky (1978) mentions that the cultural tools learners bring into the learning process are important building blocks for learning. Such tools include their cultural practices, language and artefacts, etc. The social construction of meaning therefore depends not only on human interaction but also on the environment and many other variables. When a toddler, for example, crawls under a table and hits his or her head as he or she tries to stand up, that pain becomes a learning moment that makes the child realise that he or she is taller than the object he or she crawled under. In this case, the social construction of a new idea (height in relation to self) is constructed by engaging with an object. However, this kind of knowledge requires scaffolding by skilled peers or an adult for it to become a mental process.
This article employs Vygotskian theory in investigating educators' classroom practices because it can assist in unravelling the strengths and weaknesses of their instruction. The researchers' strategy in interpreting the data collected for the purposes of this study was to employ this lens. The three main premises by Kozulin (2003), which are multiculturalism, mediation and learning potential, are viewed as the pillars of sound classroom practice. In addition, play has a significant role in this research. As indicated in the study design, the learners in the classrooms under study come from Xhosa culture, which has its own language. It was therefore deemed important to determine whether this cultural background is evident in the educators' practice. It was also critical to examine the approach the educators employ in teaching new ideas, which, in Vygotskian terms, is their mediation. Vygotsky's (1978) theory promotes the identification of the learners' learning potential, in order to direct instruction at their actual level, with the aim of moving them to their potential level. Once attained, that level becomes the (new) actual level.

\section{Grade R educator training in South Africa}

Sound nurturing of the preschool age group has multiple benefits, including enhanced cognitive stimulation, reduced remedial education costs and focused healthy and socially well-adjusted future citizens (Artmore et al. 2012; Kühne, Lombard \& Moodley 2013b; Spaull 2013). Grade R educators are pivotal in providing quality education, as they represent the most decisive and critical factors in the social, emotional and cognitive development of children (Artmore et al. 2012). When Grade $R$ educators are not properly trained, it invariably spells disaster for the country as a whole. Unfortunately, it has been established that Grade R educators in this country are poorly paid and lack the status they deserve, yet they are expected to handle learners at a delicate age, when the latter are unable to articulate their needs clearly (Excell \& Linington 2011; Fleisch 2008; Motala 2012). Internationally these educators are highly trained in mathematics content and mathematics pedagogy (Wang et al. 2003): countries like Finland require educators to have a master's degree as a benchmark qualification that goes with a high status and they receive commensurate remuneration packages (Grierson 2000). In South Africa, the opposite is the case. Research has shown that there is a cohort of Grade $R$ educators, amongst them a group currently teaching in the Eastern Cape, who received neither college nor university training [except for short induction courses with stakeholders such as non-profit organisations (NPOs)]( Artmore et al. 2012; Spaull 2011). In addition, universities in South Africa do not appear to offer specific training for educators which will allow them to manage, and implement teaching strategies for composite classes (two educators working with separate groups in the same classroom) which are more demanding than single classes (CREATE 2008). Further aggravating the situation of poorly differentiated educator practices is the fact that for a long while educators did not appear to receive the same kind of training, as there were no regularised and 
standardised courses for them. Training by NPOs and nongovernmental organisations (NGOs) appeared fragmented with each stakeholder, offering different programmes as and when funding was received (Artmore et al. 2012).

There is also evidence that South African educators are not exposed to practical demonstrations during their training, nor do they receive on-site and post-training support. This deprives them of the opportunity to handle classes while their instructors are on hand to put them through their paces (Artmore et al. 2012; Excell \& Linington 2011). This study aims to take a practical approach by using technology to mediate classroom experiences and practices and employ video as a tool for developing Grade R educators.

\section{Overcrowded classrooms}

Research on the African continent in general, and in South Africa in particular, has shown that Grade R centres do not always have the required basic infrastructure (Artmore et al. 2012; Ededeji \& Olaniyani 2011; Makori \& Onderi 2014; Siddhu 2011). It is imperative that the classroom environment should be fit for purpose, that is, learning. This means that the classroom must not be overpopulated with learners to the point where the numbers exceed the spatial dimensions of the space (Richter et al. 2012). When classrooms are so overcrowded that two groups of learners are squeezed into a space normally allocated to a single class, the environment ceases to be conducive to effective learning (Artmore et al. 2012; Ededeji \& Olaniyani 2011; DoE 2001; DoSD \& UNICEF 2010; Makori \& Onderi 2014; Siddhu 2011). As a result, simple movement, such as learners attempting to stretch their limbs or perform an activity, is stifled and learners feel caged. Even the educator's style is cramped. Research in many developing countries in Africa has revealed that overcrowded classrooms are a reality that curtails achievement, making the learning environment unsafe, inefficient, unhealthy and difficult for both educators and learners to manoeuvre in (Ededeji \& Olaniyani 2011; Makori \& Onderi 2014; Siddhu 2011). In Zimbabwe, for example, Mavundutse et al. (2012) found an untenable situation where classrooms were precariously constructed and in a state of disrepair, in addition to being overcrowded and poorly ventilated. South African schools in some situations face similar challenges, including poorly built structures that are too small to accommodate large classes (Artmore et al. 2012; Richter et al. 2012). This situation is compounded when multiple grades attempt to learn in a single classroom, leading to chaos. Educators feel overwhelmed as they attempt to navigate the physical environment, explaining different concepts to different sets of learners, and inevitably the different grades of learners end up horribly confused.

\section{Lack of structure versus use of educator-guided activities to generate enquiry and the construction of knowledge}

The Education for All (EFA) Global monitoring report (2005) notes that educators are a key enabling factor in improving the quality of education, as learning largely depends on teaching. An educator who is adequately trained and ready for a lesson will demonstrate the ability to proceed in a systematic way, following clearly defined steps (Kühne et al. 2013a). First, the educator will establish an environment that is conducive to a lesson being presented. She or he will distribute materials for the lesson well ahead of embarking on it. Guided by objectives, the educator knows the skills to be developed, motivates the learners, allows for both group and individual practice, and, finally, summarises and assesses the lesson as a whole (Kühne et al. 2013a, 2013b). The lesson should not follow a haphazard format in which the educator appears to be lost. Scholars such as Clements and Sarama (2009) and Kühne et al. (2013a) highlight the importance of organised, well-sequenced learning paths. Lessons where learners receive materials without clear instructions on how to use them end up with learners doing as they please, thus becoming educationally unprofitable (Hoadley 2013). It has also been noted that the quality of assessment, feedback and intellectual expectations in respect of Grade R learners is disturbingly low (Hoadley 2013). As a result, some lessons never feature concept development, nor do they draw the learners' attention to specific skills or knowledge in mathematics, which is advocated by scholars who urge educators to introduce concepts in a logical sequence (Kühne et al. 2013a). Consequently, when educators participating in this study were given the necessary equipment to videorecord their operations in their classrooms, some were unconcerned about showcasing themselves aimlessly babysitting the class, while the learners were left unattended and occupied themselves as they pleased. This clearly confirms the poor quality of training that the educators participating in this study received (Spaull 2013).

\section{Methodology}

The approach followed in this study is that of qualitative inquiry, which is employed to gain insights into teachers' practices. The strength of this inquiry is indicated in the use of artefacts, field notes and audio (from the videos) used as data. This was subsequently triangulated with interviews of five purposively selected educators to describe and reflect on their practices in order to strengthen the findings of the study. This approach also allowed the educators' practices and the learners' experiences to be displayed and observed via the mediation tool (video).

\section{Research design}

\section{Context}

This study was conducted in the Eastern Cape, in primary schools within a district where isiXhosa is the learners' home language. The educators participating in this study were former preschool practitioners who were later recruited to teach Grade R. All educators participating in this study had a level 4 preschool qualification, while six of them did not have a national (high school) certificate.

\section{Participants and data collection}

Fourteen Xhosa educators who predominantly teach Xhosa learners participated in the study voluntarily. These educators 
have no formal standardised teacher training. As described in the literature, they received diverse, fragmented training from NGOs. All educators have a level 4 qualification from these NGOs. Each educator was expected to select a series of five lessons that they wanted to showcase for the purposes of this research. These lessons were video-recorded by each educator from their classrooms on their own using provided video cameras. While each submitted five video lessons as part of the data collection process, only three lessons per educator were used in the end because of the poor quality of the videotaping. In addition, five purposively selected educators were asked to reflect on their practices and notes taken. Permission was received from the parents of the learners from these classrooms and the educators involved. In addition, learners gave own consent to participate. Overall permission from the Department of Education was also obtained, including the school principal's consent. An ethics application for the study was approved by the university ethics board.

\section{Instrument}

Two researchers worked separately to capture the data using the Classroom Observation of Early Mathematics Environment Teaching (COEMET) instrument, developed by Clements and Sarama (2008), using an Excel spreadsheet. In summary, COEMET was developed for the classroom observation of young learners (toddlers to 9-year-olds). This instrument measures both the quality and quantity of early mathematics learning and teaching in classrooms. In the study by Clements and Sarama, the inter-rater reliability for COEMET is $88 \%$, and the internal consistency using Rasch model is 96 (Clements \& Sarama 2008:461).

\section{Data analysis}

In this study, each researcher conducted individual coding of the data developing from both emerging patterns and contradictory phrases. Both wrote analytical memoranda defining the meaning of each pattern, which led to the origination of codes. Then, the researchers came together to share their memoranda and codes, collated them and supported the triangulated codes with empirical evidence from the data by discussing the iterative process. The triangulation resulted in the following six emerging themes: composite and crowded classrooms challenge educators; the use of resources influences learning; lack of planning and poor classroom management impede learning; demonstration can be used beneficially as a mediation tool; appropriate developmental activities lead to full learner participation; and failure to create links between concepts results in poor conceptual development.

\section{Limitations}

It is crucial to note that these findings are not generalisable as this study is qualitative. In line with qualitative inquiry tradition, the participants are few and are purposively selected. However, the study is replicable and the findings are trustworthy as triangulation was conducted.

\section{Findings}

In this section, the six themes that emerged from the analysis are discussed in greater detail.

\section{Composite classes disrupt learning}

Four of the classrooms (managed by Educators D, E, F and I) featured composite classes, where two sets of learners (i.e. different grades) attended lessons that were conducted concurrently in the same space. That involved two educators communicating to their respective groups of learners in a loud voice, or trying to compete for attention as the learners sang songs, thus creating a cacophony of noise. Figures 1 and 2 illustrate how educators tried to have some order in the composite classroom of two groups of learners. The challenges are easily shown in the picture that learners are not paying attention to their respective educators in both schools.

\section{Overcrowded classrooms create unconducive learning environments}

The classrooms were also overcrowded, with more than 50 learners per class; in the composite class, this
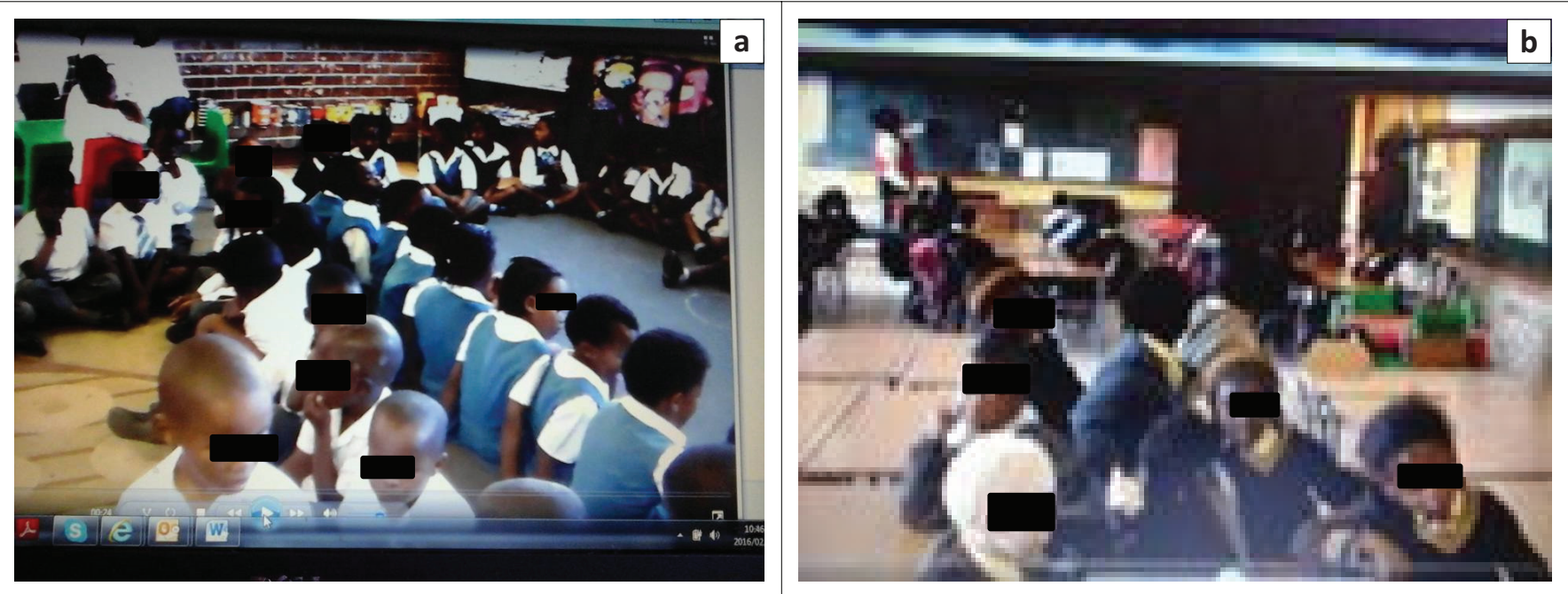

FIGURE 1: Composite classrooms. 


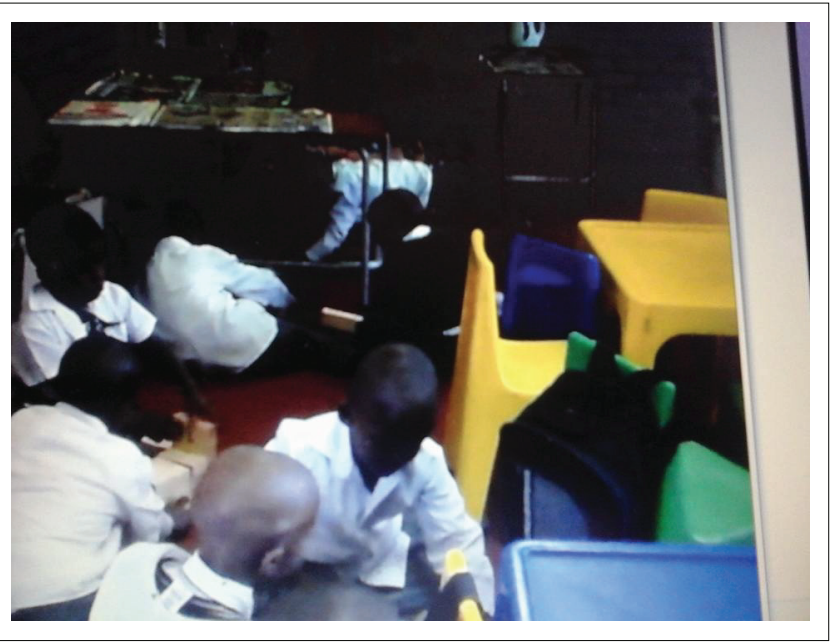

FIGURE 2: Learners ignoring instructions.

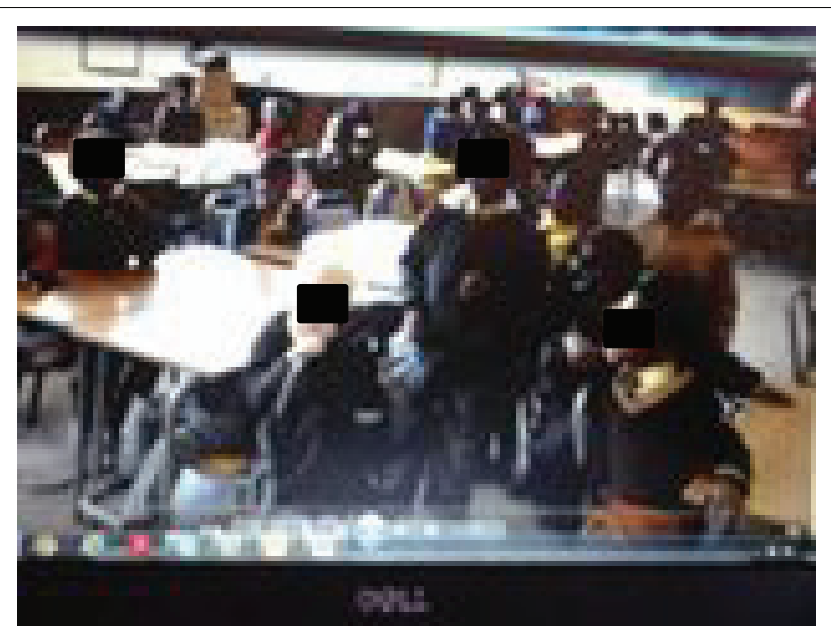

FIGURE 3: Crowded classroom with noisy learners.

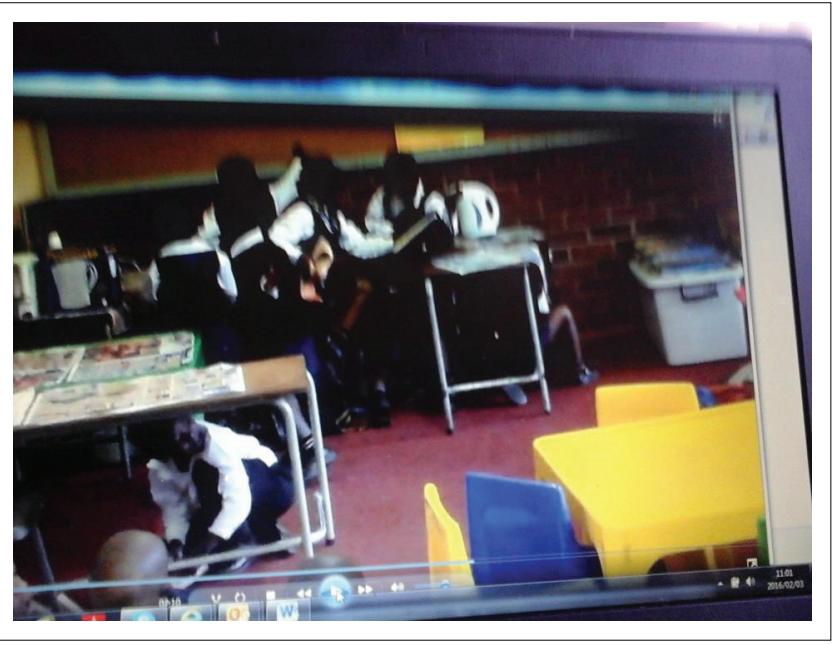

Source: Author's own work

FIGURE 4: Disruptive learners.

means around 100 learners in one setting. Inevitably, the educators failed to maintain order and the situation became chaotic. As shown in Figure 3, some learners are paying attention to the educator, while others are not. Some others just stand up randomly focusing

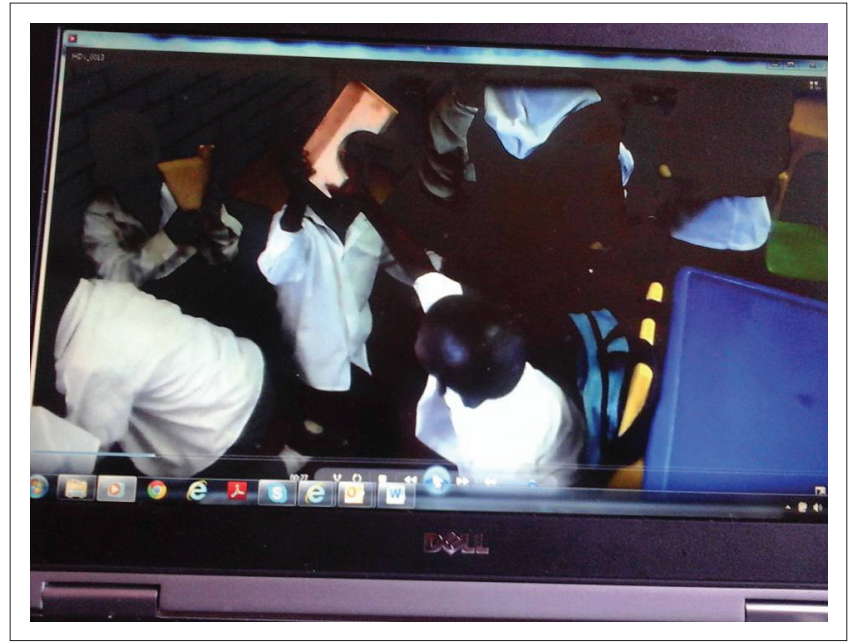

Source: Author's own work

FIGURE 5: Inattentive learners.

on what interests them rather than paying attention to the educator.

In Educator D's class, while she was trying to address one group of learners at a time, those at the back of the class became playful while others crawled under the tables (see Figures 4 and 5). Some learners pretended to be singers in a band, while others played with model cars made out of building blocks. However, when the educator came to the back of the classroom to control the disruptive learners, those left unattended in the front became noisy. As a result, the educator became agitated and had no control over the class.

The situation was also out of control in Educator E's classroom. As she engaged with learners at the front of the class, those at the back played and chatted. Some of Educator E's learners joined in singing choruses with the second group which just kept chatting and playing noisily. The scene was chaotic, with learners at the back of the classroom engaged in a variety of activities - none related to learning.

Educator F's experience was also chaotic: as she addressed one learner, the rest played energetically or sang songs accompanied by actions. In the context of the crowded composite class, this was extremely disruptive.

Educator I, who had a large class, paced up and down wasting time, eventually getting only one learner involved in telling a story to the other learners, who fiddled and chatted without paying attention to the storyteller.

\section{The learners' use of resources stimulates learning}

When the educators provided sufficient manipulatives and distributed them among all the learners evenly so that each learner could count and follow the educator's demonstrations, the lessons proceeded smoothly. It was only when counters were too few (e.g. blocks, stones or materials used to make shapes) to go around that the educators failed to encourage the learners to participate meaningfully. In fact, in some cases, 

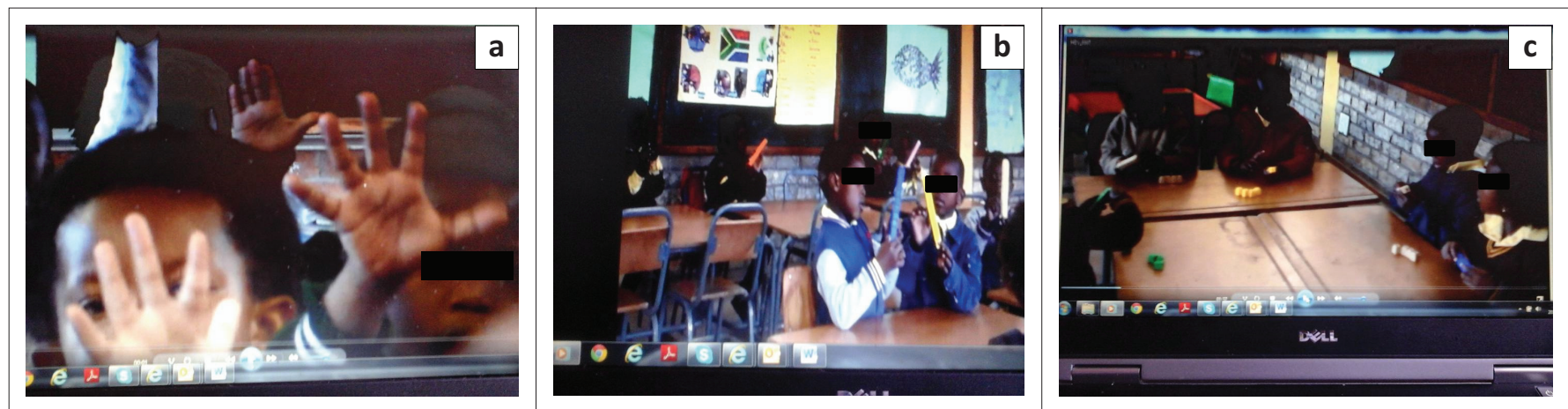

FIGURE 6: Using fingers and manipulatives to learn.

the learners started to fight over the materials and became disruptive, which derailed all of the educator's plans.

Educators A and B used manipulatives effectively and engaged the learners fully, whereas Educators $\mathrm{H}, \mathrm{N}$ and L illustrated what happens when there are insufficient manipulatives or they are improperly used. Educator A had distributed blocks to all learners before the lesson started. Consequently, the learners used the blocks as counters and were fully engaged at every stage of the lesson.

Educator B urged the learners to use their fingers as learning tools. All the learners participated in the counting lesson, raising their fingers and closely following the educator's actions, chorusing numbers as the counting proceeded (see Figure 6).

Educator L engaged only one learner at a time, who was first asked a question and then tasked with writing the answer on the board. While this was happening, however, the rest of the learners paid no attention and continued playing. Other learners simply sat staring, completely unengaged. Educator $\mathrm{H}$ actually told the learners to do as they wished. Some learners appeared to have manipulatives at hand, while others did not. The learners without manipulatives became aggressive, pushing and shoving to try and wrestle the manipulatives away from those holding them, while the latter resisted the former's efforts. One boy crawled under the table to use his block as a car and proceeded to play with it noisily, making the relevant sounds. Educator $\mathrm{N}$ simply looked on passively, with her presence in the classroom being barely noticed. She seemed to be little more than a spectator, watching learners playing with a few manipulatives, without giving them specific instructions. As a result, the lesson was a non-event.

\section{Inadequate classroom management skills impede learning}

Educators who did not plan their lessons fiddled around and wasted learning time. The learners, in turn, became disruptive and ignored the educators. This was the case with Educators E, G, I and J. Educator I initially arranged the learners in a circle, which is when they became quiet and attentive. Then Educator I proceeded to pace before returning to her chair and asking for a volunteer to tell a story about what they did at home after school the previous day. The learners reacted by looking at one another and talking quietly amongst themselves for about $5 \mathrm{~min}$, without responding to the educator. Finally, one learner stood up and shared his afterschool activities. Educator I then stood and resumed pacing, saying: 'We are waiting for our class register. While we are waiting, can someone tell us a story?' Then, the learners started chatting, ignoring their educator.

Educator G started distributing one set of manipulatives during learning time, while the waiting learners chatted and made a noise. Educator $G$ then proceeded to distribute a second set of materials, namely pieces of paper, after which she rang a bell so that the learners would stop making a noise. Next, she instructed the learners to collect the pieces of paper, but they ignored her and continued making a noise. This state of affairs continued with the educator attempting to silence the learners. She always appeared overwhelmed and the lesson was never presented.

Educator J was marking work that was not distinguishable on the videotape, but she would also pace intermittently among the learners who just sat around while the marking continued. It was not clear what the educator expected of the learners, because she failed to engage with them at all. Consequently, the learners continued chatting and doing as they pleased.

Educator $\mathrm{K}$ asked the learners to go outside and pick up papers and peels; she repeated her instruction to 'pick up the peels', but because there was no sign of fruit peels or papers outside, the learners just milled around, seeming a little lost. No learning took place at all.

\section{Mediation of external concrete ideas leads to internalised mental structures and vice versa}

Demonstrations of what to do made the taught concepts clear to the learners. Those educators who demonstrated as they spoke combined the use of visual and auditory senses so that the learners not only gained knowledge of names, vocabulary and sounds, but also connected these with concrete actions. This helped the learners to learn concepts quickly and effectively. In addition, it motivated them because they were not frustrated by challenges and failure, but could successfully follow the development of concepts. Educators A, B and C clearly used this approach. 
Educator A immediately initiated a counting activity using balls that had been distributed to each learner in advance. She proceeded to demonstrate the counting, instructing learners to follow her actions. Balls were picked to represent numbers and totals were chorused as the number of balls grew in the circles into which they were deposited.

Educator B had laid out manipulatives for each learner before the lesson began. Blocks in different colours were given to learners seated next to each other so that they did not get confused or fight over their materials. The educator led the counting by displaying the blocks and saying the numbers as the learners chorused, following the counting.

Educator C urged the learners to use their fingers to demonstrate number recognition and counting. She asked the class direct questions about how many fingers were being held up, and the learners chorused the number identified, together with the educator. After changing to block counters, the educator again proceeded to count loudly in unison with the learners as the counters were picked up. Each learner followed her example.

The educators were required to take the lead in the lessons, but conceptual links and summaries to consolidate the development of the concepts did not take place in any of the lessons. The educators did not probe learners to ascertain their understanding of concepts, nor did they make links to show how the activities they had facilitated were connected with the concepts being taught. None of the educators provided opportunities for the learners to ask questions. Learner responses to the activities were simply accepted at face value, without any discussion or reflections. In every case, the instruction was one-sided on the part of the educator.

Educator A made learners count using balls, but did not take this activity to the next level by explaining number sequences or how addition forms a pattern, such as when more balls were added to the spot where the balls were being deposited. Counting activities took place, but there was no concept clarification. Educator B did the same: the learners participated fully when counting using blocks, but the educator did not summarise the information to show how concepts were being developed. In some cases where songs and rhymes were used, the learners enjoyed singing songs that included numbers, but were not made aware of concepts such as addition and subtraction as they sang.

Instead of using blocks, Educator $C$ let the learners use their fingers to count and learner participation was high, but no conceptual development was explained. The activity proceeded smoothly, but it fell short because of lack of clarification of conceptual patterns.

The other educators neither organised activities in a meaningful way nor did they develop conceptual links.

\section{Appropriate developmental activities lead to full learner participation}

When the educators chose and used appropriate developmental activities, the learners became fully involved. Educators A, B and C selected whole-group methods so that all the learners were given instructions and each had their own manipulatives. That allowed them to participate and chorus their responses in unison, as the educator guided them. The activities that these educators had selected were appropriate for the whole class. When counting was accompanied by music, for instance, for concepts such as addition and subtraction, and where rhymes were used, learner participation was found to be optimised.

\section{Discussion}

This article highlights the unique new challenges and opportunities that educators in South Africa's Grade $\mathrm{R}$ classrooms face. The challenges include the composite nature of classrooms that impede mathematics learning completely and inadequate classroom management skills because of poor educator training. The opportunities that showed possibilities were mediation of external knowledge to internalised mental structures through the use of adequate mathematics manipulatives as well as the use of developmentally appropriate mathematics activities that stimulate learning. However, educators lacked expertise to mediate meaningfully. Most of the literature on this topic mentions only a lack of resources and overcrowding, whereas in this article we have shown that overcrowding is embedded in, and has become a symptom of, composite classrooms. This factor is significant, as Vygotsky (1978) particularly highlights the role of the school in mediating learning. If the environment is overcrowded, how can an educator give learners the individual attention they need? These findings add a new dimension to the way in which educator development should be framed, when forced to deal with overcrowded composite classrooms and at times using inadequate manipulatives. This article has also highlighted the current situation in terms of Grade R educators' poor training and remuneration, as mentioned by Richter et al. (2012). These challenges result in poor learner mathematics stimulation and indicate that resources play a significant role in young learners' mathematics development as part of the social construction of knowledge (Feza 2016; Kozulin 2003). On the other hand, simply having resources available in classrooms does not automatically translate into positive outcomes: without proper educator training, even having abundant resources will not automatically mean learners can access or use them fruitfully. Having counters, for example, does not automatically lead to counting, but learners can use counters for their imaginary ideas that have nothing to do with counting. This is similar to giving a large amount of raw meat to someone who is very hungry, but does not have the means to cook it. The composite, overcrowded classroom is highlighted as a weakness by Richter et al. (2012), who point to schools' lack of understanding of the specific needs of Grade $\mathrm{R}$ learners that involve counting through songs, play, 
rhymes, games, etc. Young learners need sufficient space to develop spatial reasoning, a safe environment and the freedom to be individuals as they learn through play, using their senses, songs, modelling and acting. Therefore, the lack of space in Grade R classrooms clearly impedes mathematics learning amongst members of this group.

While educators have shown some progress in their use of demonstration as an instructional tool that involves all learners in teaching counting concepts, they continue to neglect task assessment, which would assist them in determining whether learning has taken place or learners are mimicking. This reflects a failure to understand that learning should be directed at a learner's level of thinking, with the aim to move him or her to a potential level (Clements \& Sarama 2014; Kozulin 2003; Vygotsky 1978). Inability to create links between counting concepts results in poor conceptual development of meaningful counting. On a positive note, all the educators who used songs, rhymes, stories and manipulatives as tools for stimulating new ideas enjoyed successful learner participation, with their learners at least reaching cardinality in their counting. This study supports the Vygotskian theory of mediation, as it states that successful learning only takes place when external ideas become internal mental structures (Vygotsky 1978).

\section{Recommendations}

The insights from the research findings reflected in this article not only confirm an urgent need for the professional development of Grade R educators but also emphasise the need for educators to have the expertise of content knowledge for teaching mathematics. The findings also highlight areas that require attention in order to improve mathematics practice, such as the use of adequate materials or models and appropriateness of activities to young learners. Also the importance of standardised educator training in terms of formal programmes that need more emphasis on mathematics knowledge for teaching even for young learners has been noted. The context of inadequately trained educators operating in crowded, composite classrooms has been proven to have a negative impact on both educator practices and learners' learning and is a situation that must be remedied as a matter of urgency as mathematics becomes too much of a burden. Research has a huge role to play in this area of study. There is a need for intervention programmes that will assist the current cohort of educators within schools. More research that can inform educator practices and exploration of the method used in this study of video lessons that are selected voluntarily by educators are needed.

\section{Acknowledgements}

The authors gratefully acknowledges the financial support of the National Science Foundation, which made this work possible. All the research reflected here belongs to the author and does not in any way reflect the opinions of the foundation.

\section{Competing interests}

The authors declare that they have no financial or personal relationships which may have inappropriately influenced them in writing this article.

\section{Authors' contributions}

F.T. led the research on finding out the nature of practices of the Grade R Educators. She did the interviews that complimented the data from notes of video material. N.F. was the main researcher who initiated the Professional development project, set it up and sought the funding and ethical clearance. Both authors made notes on video clips and went on to code and analyse the data as well as analysing it and coming up with the themes that were the findings. N.F. also shaped the theoretical and conceptual frameworks. F.T. did the literature search and the two authors wrote the final report and proof reading.

\section{References}

Artmore, E., Van Niekerk, L. \& Ashley-Cooper, M., 2012, 'Challenges facing the early childhood development sector in South Africa', South African Journal of Childhood Education 2(1), 120-139.

Biersteker, L., 2010, Scaling-up early child development in South Africa. Introducing a Reception year (Grade R) for children aged five years as the first year of schooling, Wolfensohn Centre of Development Working Paper no. 17, Brookings Institution, Washington, DC.

Clements, D.H. \& Sarama, J., 2008, 'Experimental evaluation of the effects of a research-based pre-school mathematics curriculum', American Educational Research Journal 5(2), 443-494. https://doi.org/10.3102/0002831207312908

Clements, D.H. \& Sarama, J., 2009, Learning and teaching early math: The learning trajectories approach, Routledge, New York.

Clements, D.H. \& Sarama, J., 2014, Learning and teaching early math: The learning trajectories approach, 2nd edn., Routledge, New York.

Consortium for Research on Educational Access Transitions and Equity (CREATE) 2008, Increasing access through multi-grade teaching and learning, policy brief no. 5: Transitions and equity, Funded by DfID, viewed 05 February 2017, from http://www.create-rpc.org

Department of Education (DoE), 2001, Education white paper 5: Meeting the challenge of early childhood development in South Africa, Government Printers, Pretoria.

Department of Social Development (DoSD) \& UNICEF, 2010, Tracking public expenditure and assessing service quality in early childhood development in South Africa, Government Printers, Pretoria.

Donato, R. \& MacCormick, D., 1994, 'A sociocultural perspective on language learning strategies', Modern Language Journal 78(4), 453-464. https://doi.org/10.1111/j. 1540-4781.1994.tb02063.x

Ededeji, S.O. \& Olaniyani, O., 2011, Improving the conditions of teachers and teaching in rural schools across African countries, United Nations Education and Scientific Cultural Organization (UNESCO), viewed 10 January 2016, from http://nsesdoc. unesco.org/images0021/00220/2102e.pdf

Education for All (EFA), 2005, Global monitoring report: The quality imperative, UNESCO, Paris.

Edwards, S., 2003, 'New directions: Charting the paths for the role of sociocultural theory in early childhood education and curriculum', Contemporary Issues in Early Childhood 4(3), viewed 09 January 2017, from http://www.cie.sagepub.com

Excell, L. \& Linington, V., 2011, 'Taking the debate into action: Does the current Grade R practice in South Africa meet quality requirements?', SA-eDUC 8(2), 3-12.

Feza, T., 2012, 'Can we afford to wait any longer? Pre-school children are ready to learn mathematics', South African Journal of Childhood Education 2(2), 58-73.

Feza, T., 2013, 'Inequities and lack of professionalization of early childhood development \& practice hinder opportunities of mathematics stimulation and realization of South African policy on quality education for all', International Journal of Inclusive Education 18(9), 888-902. https://doi.org/10.1080/14/13600 3116.2013.85526

Feza, T., 2016, 'Basic numeracy abilities of Xhosa Reception year students in South Africa: Language policy issues', Issues in Educational Research 26(4), 576-591.

Fleisch, B., 2008, Primary education in crisis: Why South African school children underachieve in reading and mathematics, Juta, Cape Town.

Grierson, H., 2000, Early childhood education and care policy in Finland, background report prepared for the OECD Thematic Review of Early Childhood Education and Care Policy, viewed 11 July 2017, from http://www.oecd.org/finland/ 2476019.pdf 
Hoadley, U., 2013, 'Building strong foundations: Improving the quality of early childhood education', in L. Berry, L. Biersteker, H. Dawes, L. Lake \& C. Smith (eds.), South African Child Gauge, pp. 72-77, Children's Institute, Cape Town.

Kozulin, A., 2003, 'Psychological tools and mediated learning', in K. Alex, G. Boris, A.S. Vladimir \& M. Suzanne (eds.), Vygotsky's educational theory in cultural context, pp. 15-38, Cambridge University Press, Cambridge, NY.

Kühne, C., Carroll, O., Comrie, B. \& Hackman, R., 2013a, Much more than counting: Supporting mathematics development between birth and five years, The Schoo Development Unit (UCT) \& Woodworks, Cape Town.

Kühne, C., Lombard, A. \& Moodley, T., 2013, 'A learning pathway for whole numbers that informs mathematics teaching in early years', South African Journal of Education 3(2), 77-95. https://doi.org/10.4102/sajce.v3i2.42

Makori, A. \& Onderi, H., 2014, 'Examining the teaching and learning resources-related challenges facing small and medium-sized public secondary schools in Kenya: A comparative analysis', African Educational Research Journal 2(2), 72-84.

Mavundutse, O., Munetsi, C., Mamvuto, A., Mavhunga, P.J., Kangai, P. \& Gatsi, R., 2012, 'Emerging teacher education needs as a result of land reform in Zimbabwe: A focus on new resettlement areas', Academic Research International 3(2), 298-305.

Mdlongwa, T., 2012, Africa Institute of South Africa policy brief no. 80: Information and communication technology (ICT) as a means of enhancing education in schools in South Africa: Challenges, benefits and recommendations, viewed 02 February 2016, from www.ai.org.za/...No-80-ICT-as-a-means-of-enhancingEducation-in-schools-in-South-Africa-.pdf

Motala, S., 2012, A critical review of research on skills development and labour market demand in the Early Childhood Development Sector (0-4 years), viewed 20 November 2015, from www.Imip.org.za/...12\%20Shirin \%20Yousuf\%20Mtala ECD_O_pdf

Mullis, I.V.S., Martin, M.O., Foy, P. \& Arora, A., 2012, International results in mathematics, TIMSS \& International Study Center, Boston College, Chestnut Hill, MA.
NEEDU, 2013, National report 2012: The State of Literacy Teaching and Learning in the Foundation Phase, National Education Evaluation and Development Unit, Pretoria, viewed 20 November 2015, from http://www.education.gov.za/NEEDU/tabid/ v87/Default.aspx

Richter, L., Biersteker, L., Burns, J., Desmond, C., Feza, N., Harrison, D. et al., 2012, Diagnostic review of early childhood development, viewed 20 November 2015, from http://www.gov.za.za/sites/www.gov.za/files/ECD\%20Diagnostic\%Report.pdf

Samuels, M., Taylor, S., Shepherd, D., Van der Berg, S., Jacob, C. \& Deliwe, C.N., 2015, 'Reflecting on an impact evaluation of the Grade R programme: Method, results and policy responses', African Evaluation Journal 3(1), 1-10. https://doi.org/ 10.4102/aej.v3i1.139

Schmidt, W.H., Cogan, L. \& Houang, R., 2011, 'The role of opportunity to learn in teacher preparation: An international context', Journal of Teacher Education 62 138-153. https://doi.org/10.1177/0022487110391987

Siddhu, G., 2011, 'Who makes it to secondary schools? Determinants of transition to secondary schools in rural India', International Journal of Education Development 31, 394-401. https://doi.org/10.1016/j.ijedudev.2011. 01.008

Spaull, N., 2011, Primary School performance in Botswana, Mozambique, Namibia and South Africa, working paper no. 8, Southern and Eastern African Consortium for Monitoring Educational Quality (SACMEQ), Paris.

Spaull, N., 2013, 'Poverty \& privilege: Primary school inequality in South Africa', International Journal of Educational Development 33(5), 436-477. https://doi. org/10.1016/j.ijedudev.2012.09.009

Vygotsky, L., 1978, Mind in society, Harvard University Press, Cambridge, MA.

Wang, A.H., Coleman, A.B., Coley, R.J. \& Phelps, R.P., 2003, Preparing teachers around the world, Policy information report, Educational Testing Service, viewed 15 November 2015, from https://www.ets.org/Media/Education_Topics/pdf/ prepteach.pdf. 